\title{
Intravenous acetaminophen is superior to ketamine for postoperative pain after abdominal hysterectomy: results of a prospective, randomized, double-blind, multicenter clinical trial
}

\author{
This article was published in the following Dove Press journal: \\ Journal of Pain Research \\ 17 January 2014 \\ Number of times this article has been viewed
}

\author{
Hamid Reza Faiz' \\ Poupak Rahimzadeh' \\ Ognjen Visnjevac ${ }^{2}$ \\ Behzad Behzadi' \\ Mohammad Reza Ghodraty' \\ Nader D Nader ${ }^{2}$ \\ 'Iran University of Medical Sciences, \\ Tehran, Iran; ${ }^{2}$ VA Western NY \\ Healthcare System, University at \\ Buffalo, Buffalo, NY, USA
}

\begin{abstract}
Background: In recent years, intravenously (IV) administered acetaminophen has become one of the most common perioperative analgesics. Despite its now-routine use, IV acetaminophen's analgesic comparative efficacy has never been compared with that of ketamine, a decades-old analgesic familiar to obstetricians, gynecologists, and anesthesiologists alike. This doubleblind clinical trial aimed to evaluate the analgesic effects of ketamine and IV acetaminophen on postoperative pain after abdominal hysterectomy.
\end{abstract}

Methods: Eighty women aged 25-70 years old and meeting inclusion and exclusion criteria were randomly allocated into two groups of 40 to receive either IV acetaminophen or ketamine intraoperatively. Postoperatively, each patient had patient-controlled analgesia. Pain and sedation (Ramsay Sedation Scale) were documented based on the visual analog scale in the recovery room and at 4 hours, 6 hours, 12 hours, and 24 hours after the surgery. Hemodynamic changes, adverse medication effects, and the need for breakthrough meperidine were also recorded for both groups. Data were analyzed by repeated-measures analysis of variance.

Results: Visual analog scale scores were significantly lower in the IV acetaminophen group at each time point $(P<0.05)$, and this group required significantly fewer doses of breakthrough analgesics compared with the ketamine group $(P=0.039)$. The two groups had no significant differences in terms of adverse effects.

Conclusion: Compared with ketamine, IV acetaminophen significantly improved postoperative pain after abdominal hysterectomy.

Keywords: intravenous acetaminophen, abdominal hysterectomy, ketamine, analgesia, postoperative pain

\section{Introduction}

Hysterectomy is the second-most-common gynecological surgery in the United States after cesarean section. ${ }^{1}$ Nearly $40 \%$ of American women undergo hysterectomy before the age of 60 years. $^{2}$ Of the various surgical approaches to hysterectomy (abdominal, vaginal, laparoscopic, or open), the open abdominal approach has been correlated with relatively greater postoperative pain. ${ }^{3,4}$

Because these surgeries are painful, optimal perioperative pain management is of utmost importance and contributes to greater patient satisfaction, fewer adverse events, shorter hospital stays, and reduction in health care costs. Pain management can take many forms. Although systemic opioid analgesics and patient-controlled analgesia (PCA) remain at the forefront of pain management, this class of medications is
Correspondence: Nader D Nader VA Western NY Healthcare System, University at Buffalo, 3495 Bailey Avenue, Room 202C, Buffalo, NY I4215, USA

$\mathrm{Tel}+\mathrm{I} 7168628707$

Cell +l 7|6 34I 27I5

Email nnader@buffalo.edu 
associated with multiple common adverse reactions (pruritus, nausea, vomiting, constipation, respiratory complications, urinary retention, and altered mentation). ${ }^{5}$ Nonsteroidal anti-inflammatory drugs (NSAIDs), ketamine, acetaminophen, and local anesthetics have all been reported to reduce postoperative opioid consumption. ${ }^{6-9}$

Although oral and rectal forms of acetaminophen have been in use for decades, intravenous (IV) acetaminophen has only recently become available. Despite its recent introduction, it has become a routine analgesic in operating rooms and inpatient wards. Its analgesic action has not been fully elucidated, but evidence suggests that it is mediated by both cannabinoid and serotonergic pathways in the central nervous system and, to a lesser degree, though peripheral antiinflammatory effects. ${ }^{10}$ It also lowers fever by acting directly on the thermoregulatory center of the hypothalamus. ${ }^{11-13}$ Intravenous acetaminophen has been shown to have significant opioid-sparing effects for a multitude of surgical procedures, including abdominal hysterectomies. ${ }^{14}$ Clinical studies have suggested that $1 \mathrm{~g}$ IV acetaminophen is as effective as $30 \mathrm{mg}$ IV ketorolac (NSAID) or $10 \mathrm{mg}$ intramuscular morphine, ${ }^{15,16}$ but no study has compared the analgesic efficacy of IV acetaminophen with the efficacy of IV ketamine.

Ketamine is an anesthetic agent used for anesthesia, sedation, and analgesia. As an N-methyl- $D$-aspartate (NMDA) receptor antagonist, ketamine reduces the sensitivity of the central nervous system to painful stimuli. ${ }^{17}$ In this study, we hypothesized that IV acetaminophen would be more effective than IV ketamine as an analgesic and would have significantly lower sedation scores and fewer adverse effects.

\section{Patients and methods}

This prospective randomized, double-blind, multicenter clinical trial was registered in the Iranian Registry of Clinical Trials (IRCT2012103011319 N1) and approved by the ethics committee of Iran University of Medical Sciences in Tehran, Iran. ${ }^{18}$ Prospective participants were scheduled for elective hysterectomy under general anesthesia from January 1, 2012 through to December 31, 2012. Adult women aged 25-70 years were screened according to the following inclusion criteria: planned abdominal hysterectomy; American Society of Anesthesiologists (ASA) classification of 1 (normal healthy) or 2 (mild systemic disease). Exclusion criteria included the following: refusal to participate in this study; sensitivities to any of the study medications; a history of hepatic or renal diseases, seizures, alcohol or psychoactive substance abuse, and/or current smoking or opioid use; severe hemorrhage (bleeding more than 1,500 $\mathrm{mL}$ during the surgery); prolonged surgery (more than 4 hours). Patients who met the inclusion and exclusion criteria were consented to participate in this study.

All patients were premedicated with $10 \mathrm{mg}$ oxazepam administered orally the night before surgery. After being transferred to the operating room, standard ASA monitors were applied, including electrocardiography, pulse oximetry, and noninvasive blood pressure monitors. Protocol-regulated weight-based doses of midazolam, fentanyl, propofol, and atracurium were used for induction. Intubation was performed using $7 \mathrm{~mm}$ polyvinyl chloride endotracheal tubes. Anesthesia was maintained through the infusion of propofol at a rate of $100-120 \mu \mathrm{g} / \mathrm{kg} / \mathrm{min}$. Thereafter, the patients were randomly assigned to either the acetaminophen or the ketamine group using block randomization, with an equal number of participants in each group. The first group received IV acetaminophen $15 \mathrm{mg} / \mathrm{kg}$, and the second group received IV ketamine $0.15 \mathrm{mg} / \mathrm{kg}$. Both medication solutions were prepared by the research pharmacist in $100 \mathrm{~mL}$ of normal saline and were administered by the anesthesia care team within a 15-minute time period. The administering team was blinded to the nature of the infusate.

In the recovery room, an IV infusion pump (set to deliver a continuous infusion of fentanyl $30 \mu \mathrm{g}$ per hour) was connected to each fully conscious patient. Patients' levels of pain and sedation were assessed in the recovery room using a visual analog scale (VAS) and the Ramsay Agitation Sedation Scale (RASS), respectively, 4 hours, 6 hours, 12 hours, and 24 hours after the surgery. The VAS scale ranged from zero (no pain) to 10 (maximum pain). VAS scores of 1-3, 4-6, and 7-10 were designated as corresponding to mild, moderate, and severe pain, respectively. The RASS ratings were as follows: 1 (anxious and restless), 2 (calm, cooperative), 3 (responding to commands), 4 (immediate responses to stimuli), 5 (sluggish responses to stimuli), and 6 (not responsive). ${ }^{19}$

The incidence of nausea, vomiting, respiratory complications, and significant hemodynamic changes were also recorded for each group. For VAS scores greater than 3, intravenous meperidine $15 \mathrm{mg}$ was administered and the total amount administered to each patient was recorded.

\section{Statistical analysis}

The collected data was analyzed using SPSS for Windows 17.0 (IBM Corporation, Armonk, NY, USA). A pilot study of pain reported by patients after hysterectomy revealed that the average VAS score for pain was 3 with a standard deviation of 
1.4. The sample-size calculation was based on a maximum allowable difference of 1 in VAS scores. Inclusion of 40 patients in each group provided a power of 0.89 when alpha was set at 0.05 . Data remained blinded until all data were collected. Student's $t$-test and the chi-square test were used to compare numerical and categorical data, respectively, between the two groups if they had a normal distribution. Data without normal distribution were analyzed through nonparametric equivalents of the mentioned tests. Repeatedmeasures analysis of variance (ANOVA) was used to review the results at different time points. The null hypothesis was rejected at alpha ( $P$-values) less than 0.05 .

\section{Results}

A total of 80 patients met the inclusion and exclusion criteria and were enrolled in the study. No patients met the exclusion criteria for intraoperative bleeding or duration of surgery. Participants were randomly assigned to the two treatment groups, with 40 participants in each group.

There were no significant differences for age, body mass index, or duration of surgery between the acetaminophen and ketamine groups (Table 1). Although VAS scores showed temporal improvement for both groups, scores were significantly lower for each time period for the acetaminophen group compared with the ketamine group (Table $2, P<0.05$ ). Twenty patients in the acetaminophen group (50.0\%) and 29 patients in the ketamine group (72.5\%) received meperidine for breakthrough pain after surgery $(P=0.039)$.

In contrast, sedation (RASS) did not differ between treatment groups at any time point (Table 2). No significant differences in heart rate and systolic and diastolic blood pressure were observed between the two groups 4 hours, 6 hours, 12 hours, and 24 hours after the surgery (Table 3 ).

Rates of nausea were similar between the two groups. Vomiting was reported by six participants in the acetaminophen group (15.0\%) and by eleven participants in the ketamine group (27.5\%). Despite this trend, the difference between groups was not found to be statistically significant.

Table I Demographic and intraoperative characteristics of the two treatment groups

\begin{tabular}{lccc}
\hline & $\begin{array}{l}\text { Acetaminophen } \\
(\mathbf{n = 4 0})\end{array}$ & $\begin{array}{l}\text { Ketamine } \\
(\mathbf{n = 4 0 )}\end{array}$ & P-value \\
\hline Age (years) & $49.9 \pm 6.9$ & $47.2 \pm 7.2$ & 0.09 \\
$\begin{array}{l}\text { Body mass index } \\
\left(\mathrm{kg} / \mathrm{m}^{2}\right)\end{array}$ & $24.4 \pm 3.0$ & $24.7 \pm 3.0$ & 0.66 \\
$\begin{array}{l}\text { Length of operation } \\
\text { (hours) }\end{array}$ & $2.9 \pm 0.6$ & $3.1 \pm 0.7$ & 0.11 \\
\hline
\end{tabular}

Note: Data are shown as mean \pm SD.

Abbreviations: $\mathrm{SD}$, standard deviation; $\mathrm{n}$, number.
Table 2 Pain and sedation for the two treatment groups

\begin{tabular}{llll}
\hline & $\begin{array}{l}\text { Acetaminophen } \\
(\mathbf{n}=\mathbf{4 0 )}\end{array}$ & $\begin{array}{l}\text { Ketamine } \\
(\mathbf{n}=\mathbf{4 0})\end{array}$ & $P$-value \\
\hline VAS scores & & & \\
Recovery room & $5.4 \pm 2.2$ & $6.8 \pm 2.0$ & $0.004^{*}$ \\
After 4 hours & $3.8 \pm 1.7$ & $5.0 \pm 1.6$ & $0.002^{*}$ \\
After 6 hours & $2.8 \pm 1.1$ & $4.1 \pm 1.3$ & $<0.00 I^{*}$ \\
After 12 hours & $2.1 \pm 1.4$ & $3.0 \pm 1.6$ & $0.009^{*}$ \\
After 24 hours & $1.7 \pm 0.9$ & $2.3 \pm 1.3$ & $0.02^{*}$ \\
RASS scores & & & \\
Recovery room & $1.7 \pm 0.6$ & $1.5 \pm 0.5$ & 0.45 \\
After 4 hours & $2.1 \pm 0.4$ & $1.8 \pm 0.5$ & 0.32 \\
After 6 hours & $2.0 \pm 0.2$ & $1.8 \pm 0.4$ & 0.32 \\
After 12 hours & $2.1 \pm 0.7$ & $2.0 \pm 0.0$ & 0.65 \\
After 24 hours & $2.0 \pm 0.2$ & $2.0 \pm 0.0$ & 0.56 \\
\hline
\end{tabular}

Notes: Data are shown as mean $\pm \mathrm{SD}$. *Significant at $P<0.05$.

Abbreviations: $n$, number; VAS, visual analog scale; RASS, Ramsay Agitation Sedation Scale; SD, standard deviation.

Only one patient (2.5\%) in the acetaminophen group suffered from drowsiness (RASS scores of 4 or 5 ), and one (2.5\%) suffered from dizziness. No cases of drowsiness or dizziness were found in the ketamine group, but this difference did not prove to be statistically significant (Table 4).

\section{Discussion}

Postoperative pain and its complications can be attenuated with an appropriate perioperative analgesic regimen. Insufficient pain control has been suggested to contribute

Table 3 Heart rate and systolic and diastolic blood pressure in the two treatment groups

\begin{tabular}{|c|c|c|c|}
\hline & $\begin{array}{l}\text { Acetaminophen } \\
(n=40)\end{array}$ & $\begin{array}{l}\text { Ketamine } \\
(n=40)\end{array}$ & P-value \\
\hline \multicolumn{4}{|c|}{ Heart rate (beats/minute) } \\
\hline Recovery room & $89.4 \pm 14.7$ & $92.2 \pm 11.5$ & 0.34 \\
\hline After 4 hours & $83.1 \pm 9.6$ & $86.9 \pm 7.4$ & 0.05 \\
\hline After 6 hours & $81.5 \pm 7.6$ & $85.0 \pm 9.3$ & 0.06 \\
\hline After 12 hours & $81.8 \pm 8.8$ & $80.4 \pm 7.4$ & 0.44 \\
\hline After 24 hours & $80.3 \pm 6.8$ & $81.5 \pm 6.8$ & 0.43 \\
\hline \multicolumn{4}{|c|}{ Systolic blood pressure (mm Hg) } \\
\hline Recovery room & $128 \pm 14$ & $130 \pm 16$ & 0.78 \\
\hline After 4 hours & $124 \pm 12$ & $125 \pm 14$ & 0.90 \\
\hline After 6 hours & $121 \pm 14$ & $121 \pm 10$ & 0.94 \\
\hline After 12 hours & $124 \pm 15$ & $122 \pm 9$ & 0.45 \\
\hline After 24 hours & $122 \pm 12$ & $122 \pm 6$ & 0.91 \\
\hline \multicolumn{4}{|c|}{ Diastolic blood pressure (mm Hg) } \\
\hline Recovery room & $89 \pm 15$ & $92 \pm 12$ & 0.80 \\
\hline After 4 hours & $83 \pm 10$ & $87 \pm 7$ & 0.67 \\
\hline After 6 hours & $85 \pm 9$ & $82 \pm 8$ & 0.55 \\
\hline After 12 hours & $82 \pm 9$ & $80 \pm 7$ & 0.88 \\
\hline After 24 hours & $80 \pm 7$ & $82 \pm 7$ & 0.37 \\
\hline
\end{tabular}

Note: Data are shown as mean $\pm S D$.

Abbreviations: $\mathrm{n}$, number; SD, standard deviation. 
Table 4 Prevalence of side effects of medicines in the two treatment groups

\begin{tabular}{llll}
\hline Adverse events & $\begin{array}{l}\text { Acetaminophen, } \\
\mathbf{n}(\%)\end{array}$ & $\begin{array}{l}\text { Ketamine, } \\
\mathbf{n}(\%)\end{array}$ & P-value \\
\hline Nausea & $24(60.0)$ & $26(65.0)$ & 0.65 \\
Vomiting & $6(15.0)$ & II (27.5) & 0.17 \\
Dizziness & I (2.5) & $0(0.0)$ & 0.36 \\
Drowsiness & I (2.5) & $0(0.0)$ & 0.24 \\
\hline
\end{tabular}

Abbreviation: $\mathrm{n}$, number.

to various short-term and long-term complications, including poor patient satisfaction, development of chronic pain syndromes, delayed postoperative rehabilitation and patient mobilization, atelectasis, deep vein thrombosis, pulmonary embolism, psychological trauma, ischemia, and myocardial infarction. Conversely, adequate pain relief reduces patients' anxiety, morbidity, and duration of hospitalization, along with the associated costs of care. ${ }^{20}$

In addition to perioperative opioid analgesics, NSAIDs, ketamine, and local anesthetics, IV acetaminophen has been routinely administered in recent years. IV acetaminophen's relative analgesic efficacy has been compared to that of classes of medications other than ketamine. Hence, to our knowledge this study was the first to compare the efficacy of intraoperative administration of IV acetaminophen with that of IV ketamine on postoperative pain after abdominal hysterectomy.

We found IV acetaminophen to be more effective than IV ketamine administered intraoperatively for pain management after the abdominal hysterectomy. Moreover, there was a significant decrease in the administration of breakthrough analgesics (meperidine) in the IV acetaminophen group compared to the IV ketamine group. In contrast, a study comparing the effects of rectal acetaminophen with rectal ketamine on children undergoing tonsillectomy found ketamine to be superior to acetaminophen. ${ }^{21}$ This can be explained by the different administration route and the different pathophysiology of pain between tonsillectomies and hysterectomies.

The two groups had no significant differences in hemodynamics, sedation, nausea, vomiting, or dizziness. Sen et $\mathrm{al}^{22}$ and Dahl et $\mathrm{al}^{23}$ studied postoperative pain with ketamine use after hysterectomy and reported comparable rates of adverse effects. Arici et $\mathrm{al}^{24}$ also found similar rates of adverse effects, but their study compared early versus late administration of IV acetaminophen for analgesic efficacy after abdominal hysterectomy.

Although available in its oral form for decades, the recent availability of IV acetaminophen has led to much evidence-based investigation of this drug. IV acetaminophen has been found to have a more rapid onset, longer analgesic duration, and higher bioavailability than does its oral form. ${ }^{25}$ IV acetaminophen rapidly crosses the blood-brain barrier, reaches its maximal concentration in the cerebrospinal fluid, and exerts its analgesic effects through the central nervous system. ${ }^{26,27}$ In addition to its central effects, this drug has been reported to have a peripheral anti-inflammatory effect. However, this effect is somewhat limited. ${ }^{28}$

Ketamine also is generally accepted as an effective analgesic and has been used in obstetric and gynecological surgery for decades. Pain associated with surgery can be intensified by sensitizing spinal dorsal horn neurons. This process will trigger $\mathrm{C}$-fiber input and activate NMDA receptors. ${ }^{29}$ As ketamine is a well-known NMDA receptor antagonist, it is expected to inhibit this process. Kawamata et $\mathrm{al}^{30}$ showed that administration of preoperative ketamine could reduce postoperative pain in adults undergoing tonsillectomy. Suzuki et $\mathrm{al}^{8}$ confirmed this effect after outpatient surgery. Despite its history as an effective analgesic, however, ketamine was found to be less effective than IV acetaminophen in this study.

Others have also studied the effects of IV acetaminophen in gynecological surgery. Varrassi et $\mathrm{al}^{31}$ randomly allocated 200 women aged 18-70 years to two groups to receive either $1 \mathrm{~g}$ acetaminophen or $30 \mathrm{mg}$ ketorolac (NSAID) intravenously at extubation. During a 12-hour postoperative monitoring period, they found no significant differences in the required morphine dose $(10.6 \pm 4.8 \mathrm{mg}$ in the acetaminophen group versus $10.2 \pm 4.4 \mathrm{mg}$ in the ketorolac group), pain intensity, hemodynamic status, sedation, side effects, or overall efficacy of the two medicines. They concluded that acetaminophen is as effective as ketorolac in controlling pain after gynecological procedures.

Cobby et $\mathrm{al}^{32}$ compared acetaminophen to another NSAID, diclofenac, an analgesic class for which the comparative efficacy was not evaluated in our study. They investigated 72 patients with an ASA classification of 1 or 2 who were scheduled for abdominal hysterectomy under general anesthesia. The subjects were randomized to receive either $1.3 \mathrm{~g}$ rectal acetaminophen, $50 \mathrm{mg}$ rectal diclofenac, or placebo at three time points: at the end of surgery, 8 hours postsurgery, and 16 hours postsurgery. In the recovery room, intravenous PCA pumps with a $1 \mathrm{mg}$ morphine bolus, a 5-minute lockout interval, and no basal infusion were administered to all patients. The required amount of morphine was significantly lower in the acetaminophen and diclofenac groups than in the placebo group, but patients in the diclofenac group had significantly lower pain scores compared with the other two groups. 
Moon et a ${ }^{14}$ randomized 76 patients undergoing abdominal hysterectomy to receive $2 \mathrm{~g}$ IV acetaminophen or placebo 30 minutes prior to surgery; postoperative pain was measured by VAS score and PCA hydromorphone consumption was quantified by group. They found IV acetaminophen to have an opioid-sparing effect when compared with placebo, as this present study did when comparing IV acetaminophen with ketamine. Yalcin et $\mathrm{al}^{33}$ compared the efficacy of acetaminophen and ketamine for prevention of remifentanil-induced hyperalgesia in patients undergoing total abdominal hysterectomy, and found both to be similarly effective.

This prospective block-randomized, multicenter clinical trial had several limitations. One such limitation was that there was no placebo arm, thereby making it impossible to effectively state the incremental analgesic benefit of using ketamine or acetaminophen when compared with a baseline or standard of care (placebo). Another limitation was that, despite conducting this study as a multicenter clinical trial, the patient population was confined to that which is representative of hospitals affiliated with Iran University of Medical Sciences and thus may not be generalizable to other patient populations. The body mass index of each group (Table 1) may also not be representative of a global population, as there is great variability in body habitus worldwide.

\section{Conclusion}

Compared with ketamine, IV acetaminophen administered at the end of abdominal hysterectomy surgery was significantly superior for managing postoperative pain and reducing the need for rescue analgesics.

\section{Acknowledgment}

This was a $\mathrm{PhD}$ thesis in anesthesia sponsored by Iran University of Medical Sciences.

\section{Disclosure}

The authors report no conflicts of interest in this work.

\section{References}

1. Graves EJ. Detailed diagnoses and procedures, National Hospital Discharge Survey, 1993. Vital Health Stat 13.1995;(122):1-288.

2. Wilcox LS, Koonin LM, Pokras R, Strauss LT, Xia Z, Peterson HB. Hysterectomy in the United States, 1988-1990. Obstet Gynecol. 1994;83(4):549-555.

3. Hwang JL, Seow KM, Tsai YL, Huang LW, Hsieh BC, Lee C. Comparative study of vaginal, laparoscopically assisted vaginal and abdominal hysterectomies for uterine myoma larger than $6 \mathrm{~cm}$ in diameter or uterus weighing at least $450 \mathrm{~g}$ : a prospective randomized study. Acta Obstet Gynecol Scand. 2002;81(12):1132-1138.

4. Kongwattanakul K, Khampitak K. Comparison of laparoscopically assisted vaginal hysterectomy and abdominal hysterectomy: a randomized controlled trial. J Minim Invasive Gynecol. 2012;19(1):89-94.
5. Benyamin R, Trescot AM, Datta S, et al. Opioid complications and side effects. Pain Physician. 2008;11(Suppl 2):S105-S120.

6. Marret E, Kurdi O, Zufferey P, Bonnet F. Effects of nonsteroidal antiinflammatory drugs on patient-controlled analgesia morphine side effects: meta-analysis of randomized controlled trials. Anesthesiology. 2005;102(6): 1249-1260.

7. Ng A, Swami A, Smith G, Davidson AC, Emembolu J. The analgesic effects of intraperitoneal and incisional bupivacaine with epinephrine after total abdominal hysterectomy. Anesth Analg. 2002;95(1):158-162, table of contents.

8. Suzuki M, Tsueda K, Lansing PS, et al. Small-dose ketamine enhances morphine-induced analgesia after outpatient surgery. Anesth Analg. 1999;89(1):98-103.

9. Tzortzopoulou A, McNicol ED, Cepeda MS, Francia MB, Farhat T, Schumann R. Single dose intravenous propacetamol or intravenous paracetamol for postoperative pain. Cochrane Database Syst Rev. 2011;(10):CD007126.

10. Mallet C, Daulhac L, Bonnefont J, et al. Endocannabinoid and serotonergic systems are needed for acetaminophen-induced analgesia. Pain. 2008;139(1):190-200.

11. Nakamura K. Central circuitries for body temperature regulation and fever. Am J Physiol Regul Integr Comp Physiol. 2011;301(5): R1207-R1228.

12. Svensson CI, Yaksh TL. The spinal phospholipase-cyclooxygenaseprostanoid cascade in nociceptive processing. Annu Rev Pharmacol Toxicol. 2002;42:553-583.

13. Wilgus TA, Ross MS, Parrett ML, Oberyszyn TM. Topical application of a selective cyclooxygenase inhibitor suppresses UVB mediated cutaneous inflammation. Prostaglandins Other Lipid Mediat. 2000;62(4):367-384.

14. Moon YE, Lee YK, Lee J, Moon DE. The effects of preoperative intravenous acetaminophen in patients undergoing abdominal hysterectomy. Arch Gynecol Obstet. 2011;284(6):1455-1460.

15. Van Aken H, Thys L, Veekman L, Buerkle H. Assessing analgesia in single and repeated administrations of propacetamol for postoperative pain: comparison with morphine after dental surgery. Anesth Analg. 2004;98(1):159-165, table of contents.

16. Zhou TJ, Tang J, White PF. Propacetamol versus ketorolac for treatment of acute postoperative pain after total hip or knee replacement. Anesth Analg. 2001;92(6):1569-1575.

17. Petrenko AB, Yamakura T, Baba H, Shimoji K. The role of N-methylD-aspartate (NMDA) receptors in pain: a review. Anesth Analg. 2003;97(4):1108-1116

18. Research Deputy, Tehran University of Medical Sciences (TUMS). Comparison of paracetamol and ketamine for post-operative pain management in patients undergoing total abdominal hysterectomy. In: Iranian Registry of Clinical Trials [website on the Internet]. Iran; 2012. Available from: http://www.irct.ir/searchresult.php?id=11319\&number=1. Identifier: IRCT2012103011319 N1. Accessed November 4, 2013.

19. Ramsay MA, Savege TM, Simpson BR, Goodwin R. Controlled sedation with alphaxalone-alphadolone. Br Med J. 1974;2(5920):656-659.

20. Parvizi J, Miller AG, Gandhi K. Multimodal pain management after total joint arthroplasty. J Bone Joint Surg Am. 2011;93(11):1075-1084.

21. Heidari SM, Mirlohi SZ, Hashemi SJ. Comparison of the preventive analgesic effect of rectal ketamine and rectal acetaminophen after pediatric tonsillectomy. Int J Prev Med. 2012;3(Suppl 1):S150-S155.

22. Sen H, Sizlan A, Yanarates O, et al. A comparison of gabapentin and ketamine in acute and chronic pain after hysterectomy. Anesth Analg. 2009;109(5):1645-1650.

23. Dahl V, Ernoe PE, Steen T, Raeder JC, White PF. Does ketamine have preemptive effects in women undergoing abdominal hysterectomy procedures? Anesth Analg. 2000;90(6):1419-1422.

24. Arici S, Gurbet A, Türker G, Yavaşcaoğlu B, Sahin S. Preemptive analgesic effects of intravenous paracetamol in total abdominal hysterectomy. Agri. 2009;21(2):54-61.

25. Jarde O, Boccard E. Parenteral versus oral route increases paracetamol efficacy. Clin Drug Invest. 1997;14(6):474-481. 
26. Bannwarth B, Netter P, Lapicque F, et al. Plasma and cerebrospinal fluid concentrations of paracetamol after a single intravenous dose of propacetamol. Br J Clin Pharmacol. 1992;34(1):79-81.

27. Pickering G, Loriot MA, Libert F, Eschalier A, Beaune P, Dubray C. Analgesic effect of acetaminophen in humans: first evidence of a central serotonergic mechanism. Clin Pharmacol Ther. 2006;79(4):371-378.

28. Kis B, Snipes JA, Busija DW. Acetaminophen and the cyclooxygenase-3 puzzle: sorting out facts, fictions, and uncertainties. J Pharmacol Exp Ther. 2005;315(1):1-7.

29. Woolf CJ, Chong MS. Preemptive analgesia - treating postoperative pain by preventing the establishment of central sensitization. Anesth Analg. 1993;77(2):362-379.

30. Kawamata T, Omote K, Sonoda H, Kawamata M, Namiki A. Analgesic mechanisms of ketamine in the presence and absence of peripheral inflammation. Anesthesiology. 2000;93(2):520-528.
31. Varrassi G, Marinangeli F, Agrò F, et al. A double-blinded evaluation of propacetamol versus ketorolac in combination with patient-controlled analgesia morphine: analgesic efficacy and tolerability after gynecologic surgery. Anesth Analg. 1999;88(3):611-616.

32. Cobby TF, Crighton IM, Kyriakides K, Hobbs GJ. Rectal paracetamol has a significant morphine-sparing effect after hysterectomy. $\mathrm{Br} J$ Anaesth. 1999;83(2):253-256.

33. Yalcin N, Uzun ST, Reisli R, Borazan H, Otelcioglu S. A comparison of ketamine and paracetamol for preventing remifentanil induced hyperalgesia in patients undergoing total abdominal hysterectomy. Int J Med Sci. 2012;9(5):327-333.

\section{Publish your work in this journal}

The Journal of Pain Research is an international, peer-reviewed, open access, online journal that welcomes laboratory and clinical findings in the fields of pain research and the prevention and management of pain. Original research, reviews, symposium reports, hypothesis formation and commentaries are all considered for publication.

\section{Dovepress}

The manuscript management system is completely online and includes a very quick and fair peer-review system, which is all easy to use. Visit http://www.dovepress.com/testimonials.php to read real quotes from published authors. 